\title{
Influence of occupants' behaviour on energy and carbon emission reduction in a higher education building in the UK
}

Article

Accepted Version

Darby, H., Elmualim, A., Clements-Croome, D., Yearley, T. and Box, W. (2016) Influence of occupants' behaviour on energy and carbon emission reduction in a higher education building in the UK. Intelligent Buildings International, 8 (3). pp. 157175. ISSN 1750-8975 doi:

https://doi.org/10.1080/17508975.2016.1139535 Available at https://centaur.reading.ac.uk/67749/

It is advisable to refer to the publisher's version if you intend to cite from the work. See Guidance on citing.

Published version at: http://dx.doi.org/10.1080/17508975.2016.1139535

To link to this article DOI: http://dx.doi.org/10.1080/17508975.2016.1139535

Publisher: Earthscan

All outputs in CentAUR are protected by Intellectual Property Rights law, including copyright law. Copyright and IPR is retained by the creators or other copyright holders. Terms and conditions for use of this material are defined in the End User Agreement. 


\section{CentAUR}

Central Archive at the University of Reading

Reading's research outputs online 


\title{
CASE STUDY
}

\section{Influence of occupants' behaviour on energy and carbon emission reduction in a higher education building in the UK}

Howard Darby ${ }^{\mathrm{a}, \mathrm{b} *}$, Abbas Elmualim ${ }^{\mathrm{c}}$, Derek Clements-Croome ${ }^{\mathrm{d}}$, Tom Yearley ${ }^{\mathrm{e}}$ and William Box ${ }^{\mathrm{f}}$

${ }^{\text {a }}$ Centre for Technologies for Sustainable Built Environments, University of Reading, PO Box 220, RG8 6AY Reading, UK, hdarby50@gmail.com;

${ }^{\mathrm{b}}$ Peter Brett Associate LLP, London, UK, hdarby50@gmail.com;

${ }^{\mathrm{c}}$ School of Natural and Built Environments, University of South Australia, Adelaide, Australia, abbas. elmualim@unisa.edu.au;

${ }^{\mathrm{d}}$ School of Construction Management and Engineering, University of Reading, PO

Box 220, RG8 6AY Reading, UK, d.c.croome@ reading.ac.uk;

${ }^{\mathrm{e}}$ Facilities Management Directorate, University of Reading, PO Box 220, RG8 6AY Reading, UK, yearley@outlook.com;

${ }^{\mathrm{f}}$ Carnego Systems Ltd, The Old Carriage Works, Moresk Road, Truro, Cornwall TR1 1DG, UK, william.box@ carnegosystems.com

Corresponding author Email: hdarby50@gmail.com

\begin{abstract}
:
This article focuses on one of the case studies in the Carbon Brainprint research project funded by the Higher Education Funding Council for England (Chatterton, J., D. Parsons, J. Nicholls, P. Longhurst, M. Bernon, A. Palmer, F. Brennan, et al. 2015. “Carbon Brainprint - An Estimate of the Intellectual Contribution of Research Institutions to Reducing Greenhouse Gas Emissions.” Process Safety and Environmental Protection 96: 74-81). The UK total CO2e emissions in 2010 amounted to $582 \mathrm{MtCO} 2 \mathrm{e}$. It is estimated that non-domestic buildings and domestic buildings were responsible for $18 \%(106 \mathrm{MtCO} 2 \mathrm{e})$ and $28 \%(165 \mathrm{MtCO} 2 \mathrm{e})$ of these emissions, respectively. A case study method was used to investigative the opportunity of
\end{abstract}


using occupants' awareness and behavioural interventions to reduce energy use and carbon emissions in a non-domestic building of a higher education institution. An action research approach, informed by the theory of planned behaviour, was argued for this case study. It has demonstrated $20 \%$ savings in lighting, office equipment and catering energy use, largely through user awareness and behaviour change. If this level of saving were to be reflected throughout the non-domestic building stock it would represent an annual reduction in the order of $7 \mathrm{MtCO}_{2} \mathrm{e}$ in the UK. These figures relate specifically to non-domestic buildings. However, some of the techniques involved are directly transferable to domestic buildings, with the potential for further emission reductions.

Keywords: carbon emissions; building management system; intelligent buildings; occupant behaviour; sustainability

\section{Introduction}

\section{Intelligent buildings}

The term 'intelligent buildings' (IBs) was first coined in the United States in early 1980s (Clements-Croome 2004; Wong, Li, and Wang 2005) at the same time that facilities management (FM) as a profession was coming into prominence (Elmualim and PelumiJohnson 2009). It is now understood how important the influence of occupant behaviour is on energy consumption.

Modern facilities management systems (FMS) recognise this and gather feedback not only from the building systems but from the occupants as well. Advances in digital technologies and informatics, the requirement for occupant control of the local environment and the sustainability debate greatly stimulated interest and the wider implementation of IBs (Clements-Croome, in press). The application of digital technologies and informatics, including communication technology, is rapidly being deployed in FM to meet human needs. FM systems are particular types of information technology systems (IT) providing buildings, and more specifically designed IB management systems, with management and control systems (Clifford, Elmualim, and Child 2007; Elmualim and Pelumi-Johnson 2009).

The incorporation of intelligence by IT is making conventional FM more innovative. There are various research projects being undertaken to develop IB platforms, integrating building management systems (BMS) and FMS in local area networks, as well as exploiting the world wide web (internet) (Elmualim 2013; Elmualim and Pelumi-Johnson 2009). Intelligent buildings integrate sensor and monitoring technologies by data transmission 
through telephone lines, fibre optic cable or satellite uplinks. The data management systems that utilise process control and data communication to their best advantage are generically known as IBs (Clifford et al. 2007).

However, there is wide debate on the definition of the concept of IB. Wong et al. (2005) stated that there are more than thirty definitions for the concept. It is argued that the concept has evolved since it was first introduced in the 1980s (Elmualim and Pelumi-Johnson 2009; Wong et al 2005). According to The Intelligent Building Institution in Washington (1988, cited in Wong et al. 2005), IB is 'one which integrates various systems to effectively manage resources in a coordinated mode to maximize: technical performance, investment and operating cost savings, flexibility'. Another definition is that developed by the CIB Working Group W098. This definition has recognised that buildings with 'intelligence' need to respond to the change and to meet the requirement of the users. An IB should be a dynamic and responsive building that provides a productive and cost effective operation environment through optimisation among its four basic elements: places (fabrics, structure, facilities, materials), process (automation, control, systems); people (services providers, occupants); and management (maintenance, performance); and the interrelation between them (Wong, Li, and Lai 2008).

Himanen (2003) points out that 'There is no scientific definition available for the factors of the IB concepts. They are keywords, which describe common knowledge about intelligent building.' He also states 'Defining the building intelligence with the factors derived from human intelligence causes quite a change in the idea of IB concept, which has not included the factor of intelligence.' He suggests that ' $\ldots$ the essence of the intelligence behind the IB ... has been defined by the building intelligence framework, which is the interplay between the built environment in the intelligent buildings and the human intelligence'.

The concept of considering a building as intelligent can be thought of in two different ways:

- Firstly, building intelligence effectiveness. This is a measurement for the existence of building intelligence. The effectiveness comes from successful integration of systems and controls. There are features of IBs that can become effective in response to various conditions encountered. Effectiveness by control can be implemented by a multiple agent system deploying information and communication technologies. An example is the integration of daylight and natural ventilation with artificial lighting and airconditioning system. The benefit will be to maximise the usage of natural ventilation to reduce using air-conditioning and energy consumption given that external wind and 
temperature conditions prevail to drive the required ventilation.

- Secondly, buildings designed and built according to IB concepts. These concepts include, life cycle costing, marketability, the adaptability to change and to the wide range of service providers, working efficiency in meeting the requirements of the user, maintenance of equipment efficiency through FM strategies, service-orientation, an image of high technology, photovoltaics, structured cabling, information technology, productivity and construction process and structure, etc. (Himanen 2004).

Understanding the complexities of the IB concept and its relation to FM is further exacerbated by the lack of an accepted definition for FM. It is considered to be one of the fastest growing professions in the UK with an annual growth of between 2\% and 3\% (Shah 2007). Similar to IB, the concept of FM is continuously developing.

Atkin and Brooks (2005) described the concept as the integration of processes within an organisation to maintain and develop the agreed services which support and improve the effectiveness of its primary or core activities. This commonly used definition of FM has been formulated first by the European Committee for Standardisation and later formally adopted by the British Institute of Facilities Management (Elmualim et al. 2009).

Franklin Becker referred to the concept as "buildings in use, to the planning, design and management of occupied buildings and their associated building systems, equipment, and furniture to enable and (one hopes) to enhance organizations' ability to meet its business or programmatic objectives' (Becker 1991).

Himanen (2003) made reference to a correlation between IBs and value contribution, in that some building made clear and distinctive statements about an organisation's brand, although conversely branding has been maligned for producing inefficient and costly buildings. This is where FM comes into play in the strategic management of non-core activities, relating people, process and place. Appropriate strategic management will ensure the provision of space at the optimum cost and occupation at the required density, while contributing to achieving the wider aims of sustainability.

Integrated FM is the combination of IBs with FM including the utilisation of computeraided facility management (CAFM) (Elmualim and Pelumi-Johnson 2009). Over the years advanced CAFM systems have been chosen for their reporting capability (Elmualim and Pelumi-Johnson 2009; Teicholz 1992). CAFM and other and building energy management systems (BEMS) are tools for diagnosing and monitoring assets, particularly related to energy services and consumption in a building. With IB and the shift to open standards 
conformity, the BEMS will be enabled to function effectively. Strategic thinking is all about anticipating and managing change, to predict future facility needs and develop strategies that will enable timely responses (Keller and Keller 2004), particularly in reducing carbon dioxide emissions in buildings (Elmualim and Pelumi- Johnson 2009).

It is further argued that the application of CAFM and BEMS is vital to advance the cause of sustainability in FM, particularly as FM is in the forefront of achieving the organisational goals of reducing energy consumption and carbon dioxide emissions in buildings (Elmualim 2013; Elmualim et al. 2009). While it is vital to exploit IBs for sustainability, the commitment of senior management and the empowerment of FM professionals and building endusers as an integrated group are crucial to achieving an organisation's goal of carbon emission reductions (Elmualim et al. 2010).

\section{Intelligent buildings management systems}

Over the past 20 years many different buildings have been labelled as 'intelligent'. However, the application of intelligence in buildings has yet to deliver its true potential (ClementsCroome, in press). Industry has many established IB solutions but finds it difficult to demonstrate and prove their benefits. Intelligent sustainable buildings improve business value because they take into account environmental and social needs, and occupant wellbeing, which leads to improvements in work productivity (Leaman and Bordass 2006). The ideal system links the building, systems within it and the occupants so they have some degree of personal control (Clements-Croome 2004). Intelligent controls help to match demand patterns (Noy et al. 2007; Qiao et al. 2006).

To take an analogy with the brain you need good quality neural pathways and efficient junctions at the synapses but the overall performance is governed more by the connectivity effectiveness between the pathways than anything else. Like the brain, an integrated BMS allows separate systems to work together, in this case for effective building control. Recent research (Chatterton et al. 2015) using the brain analogy, proposed the concept of "carbon brainprint' through six case studies in reducing carbon emissions in higher education buildings. However, often BMS cannot meet the user expectations due to a number of challenging factors:

- The systems may be wrongly specified because of multiple stakeholders having conflicting requirements;

- The system designs have not considered usability; 
- It is difficult to reach a consensus on the criteria for optimum performance of the BMS to match the buildings behaviour;

- The lack of compatibility and inter-operability between different systems;

- Confounding factors arising from socio-economic and organisational issues can complicate the operation of the BMS.

This has contributed greatly to the 'creditability gap' in the Post Occupancy Review of Buildings and their Engineering programme that studied 23 buildings (Bordass et al. 2001). The gap between design and operation is due to the fragmentation of the industry and cultural difference and cost implications (Elmualim et al. 2009; Way and Bordass 2005). Furthermore, clients and their building designer do not invest in post-occupancy evaluation studies of their assets as it is difficult to establish who should pay and who should conduct such studies (Bordass and Leaman 2005).

Intelligent buildings aim for simplicity of operation. Passive design uses a blend of high and low technology such as orientation of building and fabric, which is an important feature. Passive environmental control methods ensure that active systems have lower power requirements so that selecting appropriate technologies to provide ventilation, heating and cooling is paramount. A mix of automatic and manual control of the environment can both minimise energy consumption and enhance occupant well-being, using a high degree of personal control. The performance of a building can be enhanced further by intelligent control strategies that use existing and emerging technologies such as smart metering.

Control systems and communication networks are rapidly developing and, in the near future, one can expect to see the occupant having more control and interaction with the building and systems. The work of Liu et al. (2008), Booy et al. (2008) and Qiao et al. (2007) show how more personal control may be achieved by adopting a multi-agent system for building operation (MASBO) using semiotic modelling. The primary objective of MASBO is to support the effective management of sustainable energy performance, while taking into account occupant well-being and productivity.

There will be a constant interplay between a building and its occupants, as they affect each other. Once entering a building, an occupant is submerged in a pervasive space in which interactions take place (Duangsuwan and Liu 2008). However, how does an occupant respond to the changing patterns of these factors? Subjective reactions also need to be assessed by questionnaires, auditing or by the sense diary to record occupants' satisfaction and sensory well-being. The data collected allows FMs to improve the 
conditions for the occupants as well as engaging them to mechanism to reduce energy consumption. Such as using posters next lighting control to encourage occupants to switch off lighting when meeting rooms are unoccupied (Tetlow et al. 2014).

Various technologies are utilised in collecting such invaluable information about buildings and its' occupants and their behaviour. The increasing miniaturisation of radiofrequency devices and micro electro-mechanical systems, as well as advances in wireless technology, have generated a great deal of interest in wireless sensor networks (WSN) due to the fact that they can provide an infrastructure for gathering information about the physical world, including equipment and the behaviour of people. Recent advances in WSN technology have enabled the development of small, low-cost, low-power, multi-functional sensor nodes that allow communication over short distances. By connecting a WSN to actuators in a building, a wireless sensor actuator network can be built up. These not only collect information on indoor environmental variables, they also control the environmental systems using what is terms intelligent post-occupancy evaluation studies. This creates a real-time, closed-loop control system, in which the occupants are included, so that the pattern of interactions between the occupant, the systems and the building can be analysed (Elmualim 2013). People are slowly learning about their energy consumption patterns as internet data management systems are becoming available for the domestic consumer as well as for other building types (Beart 2010). This will have a great impact in occupants' engagement particularly in reducing energy consumption and carbon emissions.

\section{The case study and the IB concept}

As has been stated this case study formed part of a joint research project termed 'carbon brainprint' aiming at quantifying and reducing carbon emissions in Higher Education institutions in the UK (Chatterton et al. 2015) financed by the Higher Educarion Funding Council for England. The case study reflects the concept of IB in that it introduces a practical, transparent and innovative method of reducing a building's energy use, simple in operation and which takes into account cultural and sociological issues. By monitoring daily energy use and automatically feeding back this information directly to the users by facilities managers, a closed-loop feedback system is introduced, in which the occupants are included and given a degree of personal influence and responsibility for the energy performance of the building.

This type of system informs people about their energy use, and can help to embed cultural energy saving behaviour. It involves management, FM professionals and building 
end-users as an integrated group in an effort to close the 'creditability gap' between design and operation carbon emission (Aghahossein et al. 2015).

\section{Methodology}

The methodological approach is based on Action Research (Rapoport 1970; Stringer 1999). Action Research as an epistemological position, which allows change in the dynamics of a research situation - a higher education establishment in this case. It involves the process of research with active participation of all stakeholders in changes to an organisation's practices, with the aim of improving the performance of an organisation. As designer and stakeholder, researchers work with others to propose a new course of action to help their community improve its work practices. Action research adopts a non-competitive approach in order to enhance the experience and the lives of all participants, including the researchers. The researchers are seen as facilitators for the research, promoting positive relationships through effective, constant and inclusive communication (Stringer 1999). The approach is cyclical in nature and is further informed by the theory of planned behaviour (TPB) as shown in Figure 1 (Ajzen 1991). TPB stipulates that human actions are determined by conscious intention due to a combination of three behavioural constructs: attitude, subjective norms and perceived behavioural control. By quantifying these three predictors the likelihood that an individual will carry out a particular action can be estimated and influenced by Actual Behavioural Control as can be seen in Figure 1. Additionally, if these predictors can then be subsequently adjusted (i.e. through behavioural interventions such as posters/nudges (Figures 4 and 5) the possibility of the action being performed can be directly influenced.

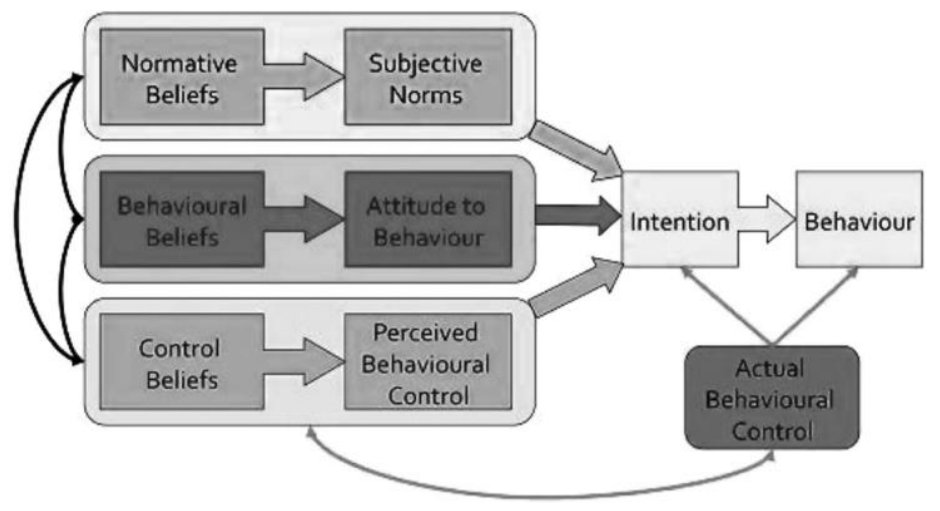

Figure 1. TPB - Feedback cycle (Ajzen 1991). 
A case study based method has been adopted (Yin 2009) as part of the 'carbon brainprint' project (Chatterton et al. 2015) This case study considers an approach to reduce energy use in The Carrington Building at the University of Reading (UoR), by influencing the behaviours of building users. It is part of a wider energy reduction project by the university's FM team, involving a number of buildings on the Reading campus. The Carrington Building is a modern, three storey office block, completed in September 2007, housing the university's student services (Figure 2).

The user population consists of office-based university staff with students coming to the building with queries (e.g. housing, finance, etc.). There are also a number of meeting rooms that are available for use by staff across the campus.

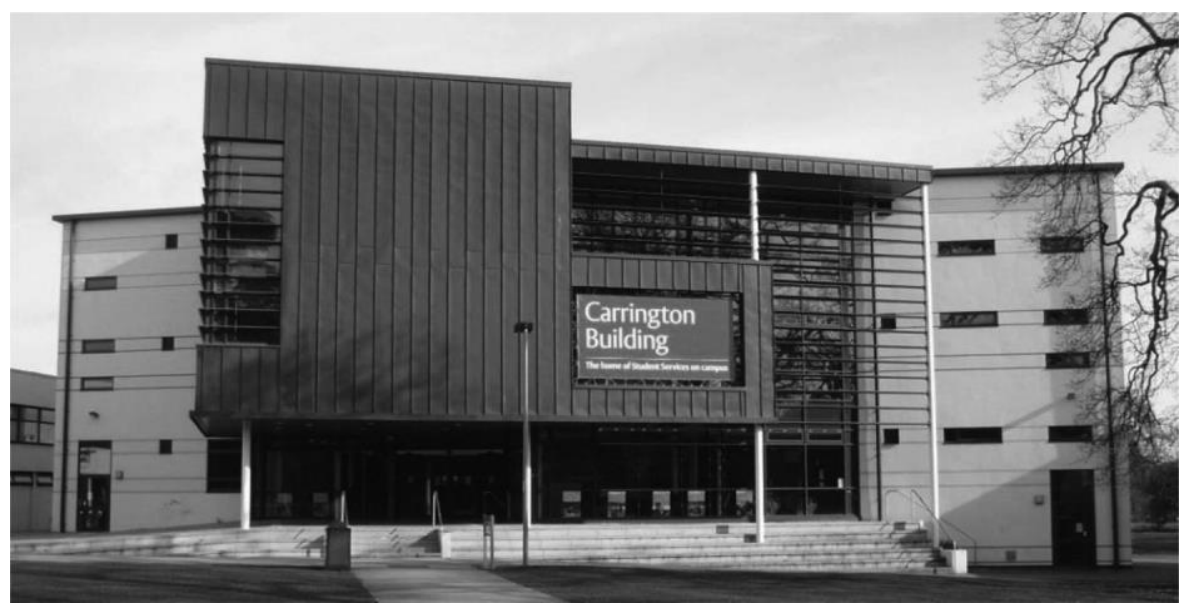

Figure 2. The Carrington Building. 


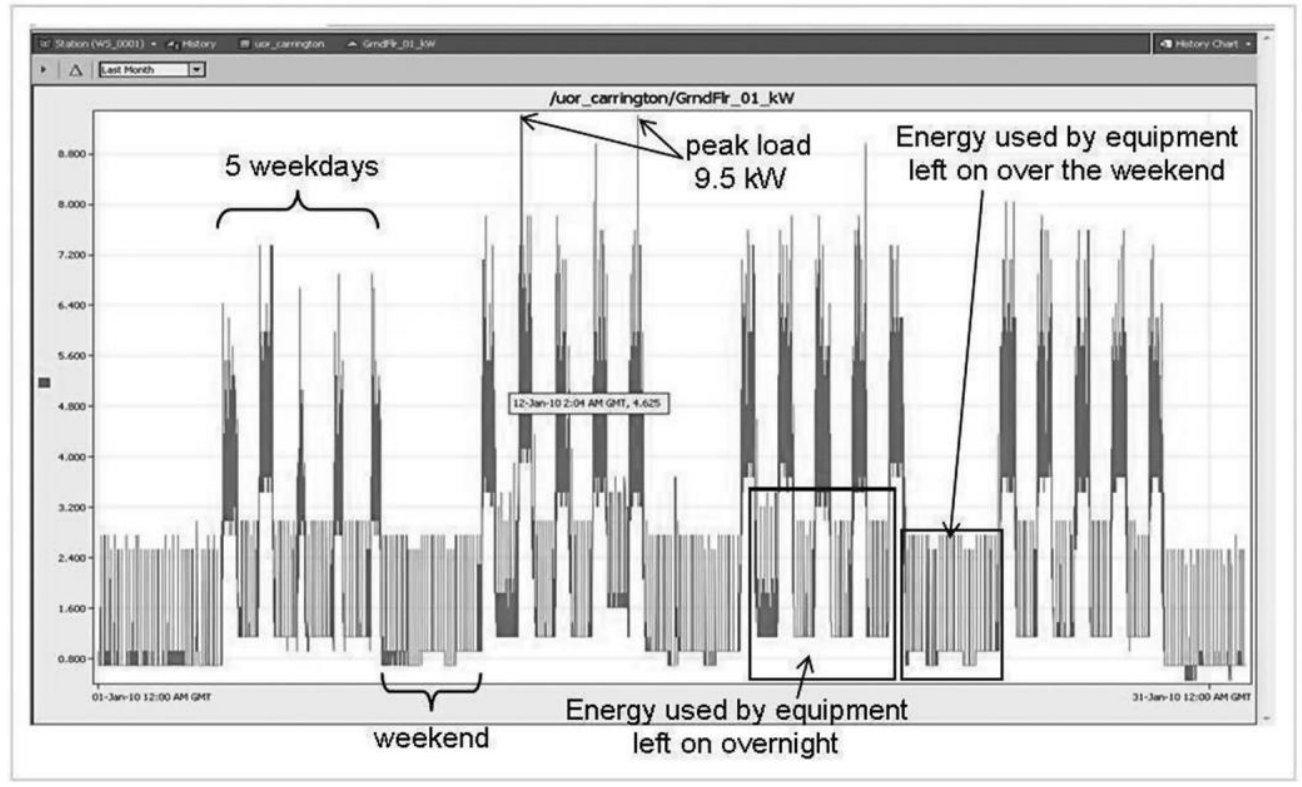

Figure 3. Example of a detailed energy trace.

The study is a continuing long-term project but this article considers the results from a limited initial period from October 2009 to April 2011.

\section{Theoretical approach}

The key feature of the case study is the attempt to complete a feedback cycle identified by the methodological approach that is often missing in the relationship between the building and the users. This feedback cycle is described by the steps listed below informed by Action Research and the Theory of Planned Behaviour:

1. Collect detailed, granular data on energy use;

2. Process and analysis this data to produce meaningful information;

3. Present the information to users in ways that can be understood and that prompt action;

4. Implement the actions;

5. Keep going round this loop on a continuous basis, improving and reinforcing behavioural change. 

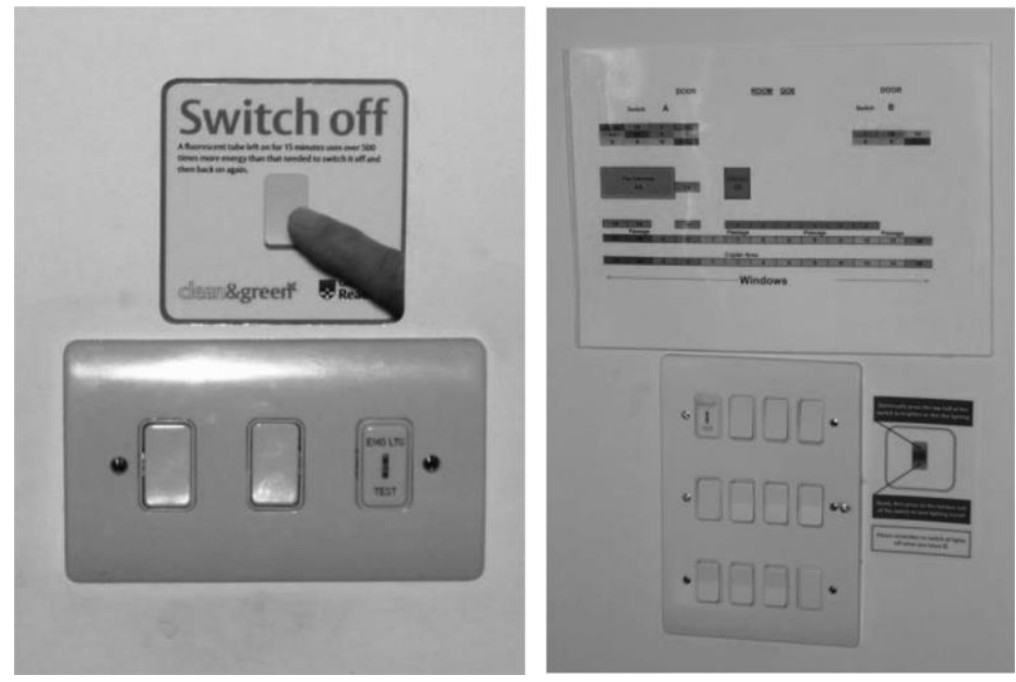

Figure 4. Typical light switch signs.

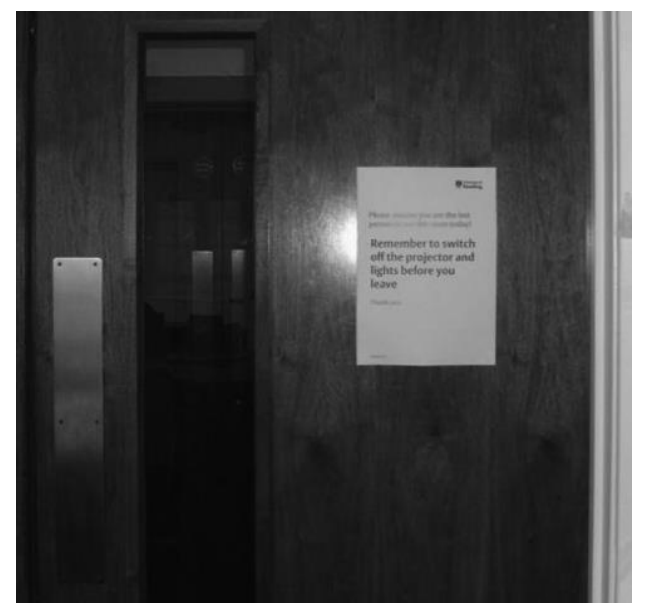

Figure 5. Typical room sign.

The factors which are important to recognise in the model of TPB are that:

1. There must be some means by which users can technically exercise control over their environment. This can be as simple as a light switch / being able to shut down computers or as complex as settings in the building management system. It is critical that some means does exist, even if the user does not know how to use it to begin with; 
2. The users believe they can exert some control over their environment that will make a difference. Here the users must understand what they can do, be confident in doing it and be motivated to do it. This is a key part of the behaviour change process and the issue of perceived control is often under-represented in other approaches;

3. The individuals, their individual beliefs and individual behaviours must be addressed. Whether people are trying to save money or save the planet, their individual beliefs and behaviours are clearly important. In some approaches however, this factor can be over-emphasised and all of the focus put on individual beliefs and actions;

4. The social context of the users must be taken into account. By recognising the groups that the user belongs to, we can try and influence the 'norms' within these groups in terms of beliefs and behaviours. Changing these 'norms' for the group as a whole is a key element of achieving long-term sustainable change. We want people to instinctively do things because that's what 'we' as a group do.

\section{Monitoring and data collection}

Monitoring equipment was installed during October 2009 to collect detailed energy data. Whilst some sub-meters were in place within the building, they did not cover all areas and they were supplemented with wireless current transducers (CTs). Energy data could then be collected as follows:

- Sub-metering

- Ground floor west

- First floor west

- Second floor west

- Roof mechanical plant

- Basement mechanical plant

- Wireless CTs

- Ground floor east

- First floor east

- Second floor east 
Monitoring was limited to combined lighting and small power, including office computers and equipment, fridges, water heaters, kettles and supplementary electrical heating and ventilation. Due to the electrical layout on the main floors, it would have been cost prohibitive to separate the two items. In buildings, subject to Part L of the 2006 Building Regulations, it would be normal to have lighting, small power, mechanical plant and other key uses separated, which would allow more detailed monitoring. The lift, emergency lighting and electricity demand from the ground source heat pump heating system were not included. Apart from the lifts these items would not have offered the opportunity for user control. The monitoring equipment was fitted using the university's facility management electricians, and a team of two completed the installation in less than three hours.

Data is collected at one minute intervals using CTs or five minute intervals using submeters and transmitted back to the central database and application suite, using a general packet radio service (GPRS) (mobile phone) connection. This data is available for viewing via a secure online application and for download in csv format for use in Microsoft Excel spreadsheets. This frequent collection of data gives a very detailed picture of energy use within the building, allowing precise reduction targeting. An example of the type of detailed energy trace achieved is shown in Figure 3.

Initial user behaviour was observed during a number of walk-around visits of the building between July 2009 and January 2010. The following observations were made:

- Lighting was continually 'on' even on bright sunny days. It was switched on when people came into the building and not necessarily turned off when people left in the evening. It was reported by users, that turning the lights on was a reflex action and was given little rational thought.

- There was an impression that general lighting levels were excessively high.

- Office equipment (PCs, photocopiers, etc.) were sometimes switched off, but often left on, or on standby.

- Some users were aware that the building was designed to be 'environmentally friendly' but this seemed to encourage the belief that individual efforts to conserve energy in the building were less important.

Prior to any interventions, baseline data was collected during the autumn term and over the Christmas break (October to the end of December 2009). 


\section{User engagement}

On 25 January 2010, the project team started engagement with the building users. Initially the main focus was with the Building Manager (BM) and the Deputy Building Manager (DBM). Management of the building was an additional responsibility over and above their normal duties and, although the BM was 'on board' from the start, the DBM was more sceptical.

The initial conversations concentrated on demonstrating the level of monitoring being carried out and how a detailed energy trace could be used to determine many things about the energy use in the building. Some of the issues identified in this way were:

- Water heaters were left on 24 hours per day, 365 days per year.

- The 'base load' at night varied depending on whether users left things on or not when they left the building.

- Vending machines on the first floor were very active and significant consumers of energy.

This process enabled the project team to gain increased support from the BMs and showed them the potential level of control they had over the building and its energy use. Subsequently the BMs have worked with the project team to implement a number of interventions within the building and to encourage other building users to participate. The BMs continued to have access to the detailed live energy traces for the different parts of the building and thereby were quickly and easily able to see the results of their actions.

\section{Interventions}

\section{Vending machines}

Once the BMs could see the effect of the vending machines on the first floor energy trace, they determined that these machines were not actually required in the building and they were removed. No user dissatisfaction has been reported associated with this change. This was one of the earliest interventions and enabled users to see the resulting, immediate, reduction in energy use, and provided positive reinforcement to help with the promotion of other interventions. 


\section{Water heaters}

The monitoring identified a set of water heaters that were on continuously. In the west end of the building these were located in the staff kitchens for making hot drinks. They were found to be fitted with time clocks but these were not set. They were then set to be on only during the expected hours of building use. In the east end of the building there are no kitchens.

However, the data showed energy traces consistent with continuous water heater use. This led to the BMs discovering water heaters inside the cleaning cupboards on each floor, continuously on and supplying small amount of hot water for the cleaners to use. These were also subsequently set to provide hot water only when required. Other water heaters for washing were also brought under control of the main building management system.

\section{Water coolers}

Prior to user engagement, water coolers were left switched on continuously. These are now on time switches.

\section{Lighting}

During the walk-around visits, it had been established that the standard behaviour was for lights to be put on at the start of the day and not necessarily turned off at the end. This type of behaviour appears to have been consistent throughout the year, and during the visits there had been an impression that the general lighting levels in the building had been excessively high.

Behaviour change has been addressed mainly by the 'out of hours initiatives' described in Section Weekend switch-off, but in addition switch-off signs and switch/lighting layout plans have been placed alongside light switches (Figures 4 and 5). Signs have also been placed in rooms with intermittent use, encouraging users to switch off when leaving.

A new energy efficient upgrade to the lighting system was completed on 9 July 2010, designed to provide further energy savings. This included PIR and daylight sensors in the main offices to allow precise automatic control of lighting levels in the areas adjacent to the north facing windows (Figure 6), and dimming controls to allow direct adjustment by users (Figure 4). 


\section{Out of hours initiatives}

It appeared from the baseline data that there was considerable scope for energy savings outof- hours, at night and over the weekends, and this was the area which the project team focused on to achieve the first phase 'easy win' reductions.

Weekend switch-off. The first direct communications with all building occupants took place on 27 and 29 January 2010. These were emails giving details of a trial weekend 'switch-off' on 30 and

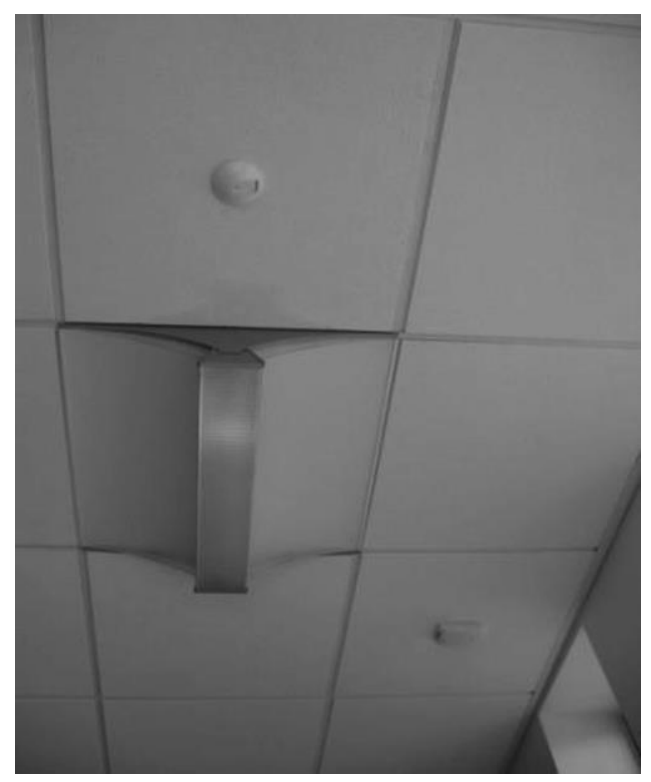

Figure 6. Lighting and PIR sensors.

31 January 2010. The trial was carried out to establish the level of energy reduction that could be achieved if users made a concerted effort to switch-off equipment. Items in the campaign included lights, personal and other PCs, photocopiers, printers, display screens, shredders and hot drink water heaters. The results showed that the switch-off led to a reduction in weekend, and sub-sequent night-time, base load energy consumption. The trial was followed up with the first 'switch-off' plan (Figure 7), issued by email on 16 March 2010 and posted on notice boards, together with Friday email reminders to try and develop long-term behaviour change. To avoid 'reminder fatigue', the Friday emails are issued only on a semi-regular basis. 
Automated feedback. Although the live data was useful for the BMs, a system of daily reporting of energy performance has been developed to serve as a simple feedback mechanism for both the BMs and other users of the building. Energy use during the out-ofhours periods is monitored and compared to previous nights/weekends. Based on the previous minimums, each area of the building is reported as 'on target', 'near target' or 'offtarget'. This information is sent to the BMs in a short email each morning, prompting them to investigate and remedy any 'near target' or 'off-target' reports. An example email is shown in Figure 8.

STUDENT SERVICES DIRECTORATE

\section{Carrington Building Switch off Plan}

March 2010

\begin{tabular}{|c|c|c|c|c|}
\hline \multirow[t]{2}{*}{ Item } & \multicolumn{4}{|c|}{ I can safely turn this off... } \\
\hline & -after using it & $\begin{array}{l}\text { at the end of } \\
\text { the day }\end{array}$ & $\begin{array}{l}\text {.before } \\
\text { leaving for the } \\
\text { weekend }\end{array}$ & $\begin{array}{l}\text { before } \\
\text { leaving for } \\
\text { holidays }\end{array}$ \\
\hline Lights & $\begin{array}{l}\text { Istaff room } \\
\text { meeting rooms } \\
\text { etx) }\end{array}$ & $\checkmark$ & $r$ & $\checkmark$ \\
\hline Personal PCs & & $\checkmark$ & $\checkmark$ & $\checkmark$ \\
\hline $\begin{array}{l}\text { PCs in interview } \\
\text { rooms }\end{array}$ & & $\checkmark$ & $\checkmark$ & $\checkmark$ \\
\hline $\begin{array}{l}\text { Banks of PCS } \\
\text { (e.e. CAS Resource } \\
\text { Ubrary/Student Sell. } \\
\text { Service) }\end{array}$ & & & $\checkmark$ & $\checkmark$ \\
\hline Photocopiers & & $\checkmark$ & $\checkmark$ & $\checkmark$ \\
\hline Printers & & 1 & $\checkmark$ & $\checkmark$ \\
\hline Fax Machines & & & & $\checkmark$ \\
\hline Water Coolers & & & $\gamma$ & $\checkmark$ \\
\hline $\begin{array}{l}\text { Plasma Display } \\
\text { Screers }\end{array}$ & & $\checkmark$ & $\checkmark$ & $\checkmark$ \\
\hline Shredders & & $\checkmark$ & $\checkmark$ & $\gamma$ \\
\hline $\begin{array}{l}\text { Hot drinking water } \\
\text { heaters }\end{array}$ & & $\checkmark$ & $\checkmark$ & $\checkmark$ \\
\hline
\end{tabular}

If you are last to leave at the end of the day please remember to switch off the lights and equipment in your work area.

If you think of anything that could be added to this list email d.doylepreadingaciuk.

Figure 7. Switch-off Plan. 
Sent: 10 March 2011 08:01

Subject: Carrington Energy Monitoring

Good morning,

This is the latest update on the energy performance

of the Carrington building during the last 'out of hours' period.

Areas on Target:

* Ground Floor West

* Second Floor West

* First Floor West

Areas near Target:

* Second Floor East

Areas NOT on Target:

* First Floor East

* Ground Floor East

To access Star Chart click

http://www.carnegosystems.com/uor/carrington/Star_Chart.html

If you have any queries regarding these results, please email

support@carnegosystems.com

Figure 8. Daily energy performance email.

The automated emails are supplemented with 'star charts', showing the performance of the different areas of the building in an easily assimilated visual display, which aims to encourages an element of competition and help develop long-term behaviour change. An example start chart is shown in Figure 9. 


\section{Other interaction with users}

The Project Team and the BMs regularly circulate other 'green' emails to the building users in order to foster a continuing interest in environmental and energy issues, such as:

- Use of double sided photocopying;

- Recycling;

- The UoR 'Green Impact Award Scheme’;

- Appointment of ‘Environmental Champion's for each floor;

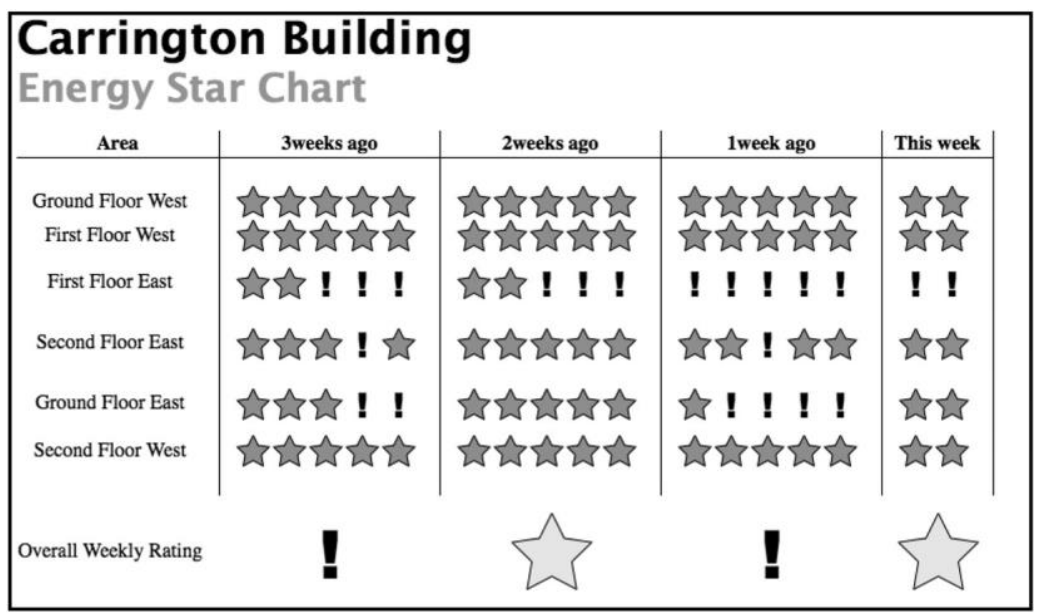

Figure 9. Star chart.

- Announcement of 'Green and clean' areas';

- 'Sustainability Matters' and 'Travel Wise' newsletters;

- The 'Green Pledge' for individuals;

- Earth Day;

- the 'People and the Planet' green League;

- ‘Big Tidy Up’ litter picking;

- Reading Buses ticket offers;

- Green Week. 


\section{Results}

Results from the start of monitoring in October 2009 through to April 2011 are shown in Figure 10 and Table 1. Figure 10 gives daily electricity consumption for both 'occupied' (red) and 'unoccupied' (blue) days, together with respective daily mean for each month. Also shown are the dates of the initial monitoring (vertical blue lines) and the various interventions. The latter are split into interventions and communications specifically related to energy saving (vertical red lines), and other environment related or 'green' topics, such as recycling, green travel plans and Green Week (vertical green lines). 'Occupied' is defined here as a twenty four hour normal working day, including 'out of working hours' periods at the start and end of the day. While 'unoccupied' is defined as a twenty four hour weekend day or public/university holiday. There is a distinct reduction in both 'occupied' and unoccupied' electricity use over the period February 2010 to April 2010, which coincides with the time of the first engagement with the FMs, the first communications with other building users and the start of the weekend switch- off. The level of consumption has remained relatively stable since, but with some variation. This appears to be seasonal and associated with generally improved daylighting in the summer months and with the summer holiday period, when fewer permanent staff are present and there is less student activity.

\section{Unoccupied}

The initial weekend switch-off trial showed a reduction in electricity use of around $26 \mathrm{kWh}$, from 161 and $160 \mathrm{kWh}$ on Saturday and Sunday (24 and 25 January 2010) down to 143 and $152 \mathrm{kWh}$ on Saturday and Sunday (24 and 25 January 2010), representing a reduction of around $8 \%$, equivalent to $8 \mathrm{~kg} \mathrm{CO} 2 \mathrm{e} / \mathrm{day}$. Subsequently, this has reduced further and levelled out at between $105 \mathrm{kWh}$ to $121 \mathrm{kWh}$ per day, which is a saving of between $34 \%$ and $24 \%$ compared to pre-project use, equivalent to between 34 and $24 \mathrm{~kg} \mathrm{CO} 2 \mathrm{e} / \mathrm{day}$. This further reduction appears to be due to a combination of the FM's 'building set up' interventions, such as removing vending machines and setting time switches for water heaters, and other building users acting in line with the switch-off plan. Holiday periods, such as Christmas and New Year, generally show lower consumption than weekends. For example, prior to the project start the Christmas and New Year mean daily use was 113 $\mathrm{kWh}$ compared with $160 \mathrm{kWh}$ at weekends. 


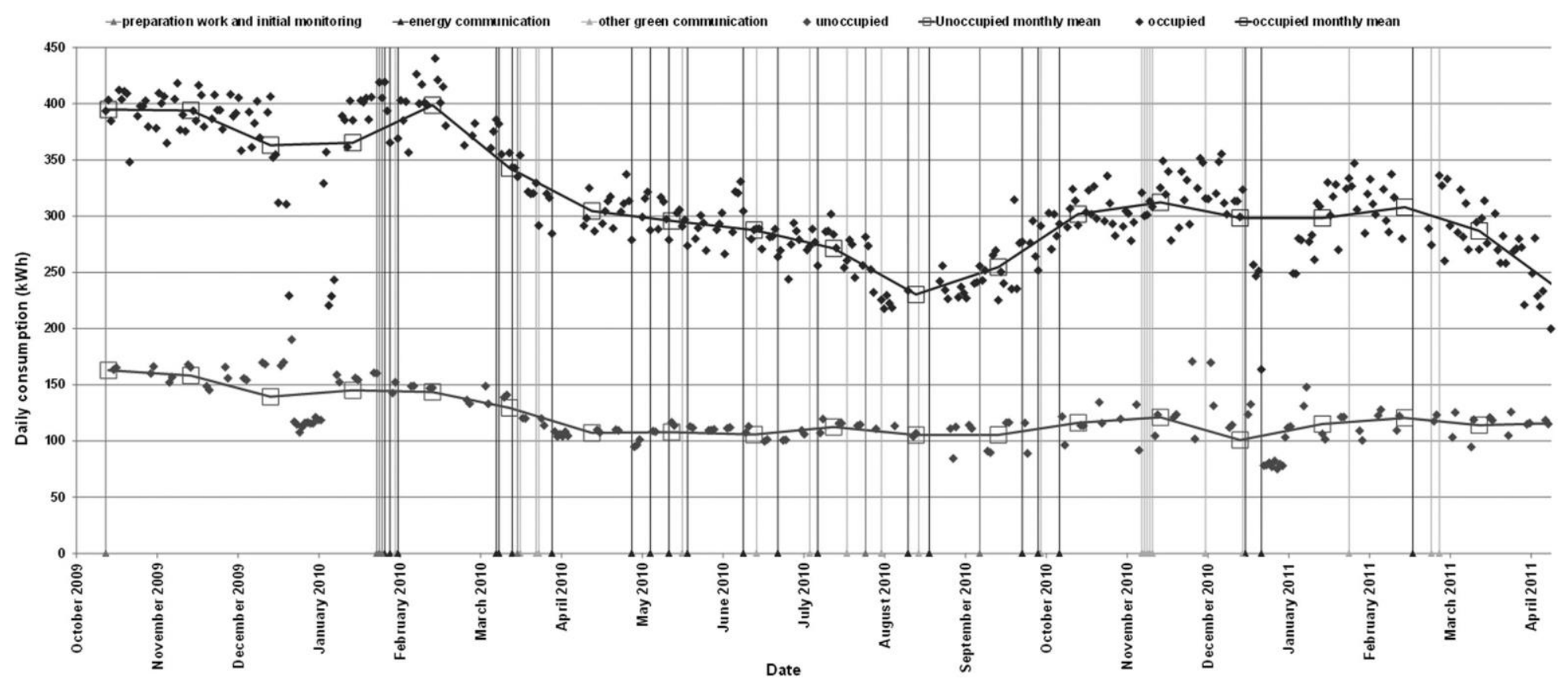

Figure 10. Daily energy consumption, occupied and unoccupied and interventions. 
Table 1. Mean daily electricity consumption, and electricity and carbon dioxide emission savings compared to the previous year.

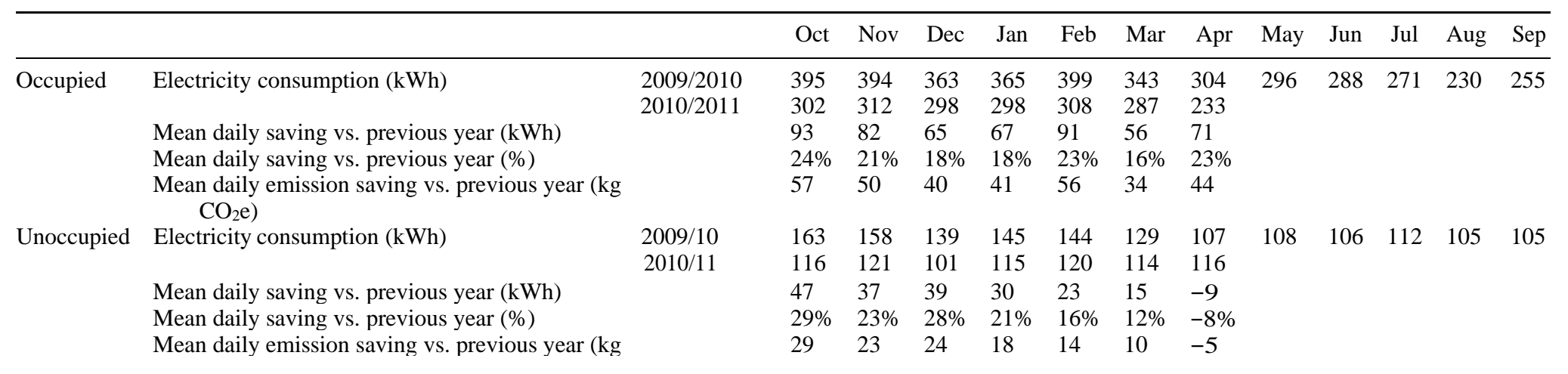

\section{$\mathrm{CO}_{2} \mathrm{e}$ )}

Note: Greenhouse gas emissions conversion factor for grid electricity $=0.61707 \mathrm{~kg} \mathrm{CO}_{2} \mathrm{e}$ per $\mathrm{kWh}$. 
The corresponding figures since April 2010 are 87 and $111 \mathrm{kWh}$. The switch-off plan is the same for weekends and holidays, so it is not clear why this difference occurs. Detailed information relating to weekend use of the building is not available, but it is thought likely that the difference is due to some limited use of the building during weekends together with possible increased 'switch-off' awareness before holiday breaks. The daily mean electricity use for each month was calculated, arranged for ease of comparison between corresponding months for each year, reducing the apparent distortion from seasonal effects. To date, results for the second year (2010/2011) are only available up to midApril. The results show reductions of between $21 \%$ and $29 \%$ for the 'baseline' months of October to January, equivalent to reductions of 18 and $29 \mathrm{~kg} \mathrm{CO} 2 /$ day. Lower reductions occurred in February and March, which would be expected as the first year (2009/2010) figures already include some of the initial reductions. However, in February, March and April 2011 there does appear to be a slight upward trend in electricity use. Unlike the April 2010 figure, the April 2011 figure does not yet include the Easter Holiday break, which is likely to be lower than weekend use, leading to a likely reduction in the mean value.

\section{Occupied}

The distinct reduction in 'occupied' electricity use over the period February 2010 to April 2010, again appears to be due to a combination of the FM's 'building set up' interventions, which in this case also includes the removal of unnecessary light bulbs, and the work day 'out of hours' switch- off. The result (Table 1) shows reductions of between $24 \%$ and $18 \%$ for the 'baseline' months of October to January, equivalent to reductions of 57 and $41 \mathrm{~kg}$ $\mathrm{CO}_{2} \mathrm{e} /$ day. In this case, the percentage reductions have, to a large extent, been maintained through February, March and April 2011. This may be due, in part, to the lighting upgrade completed on 9 July 2010. There is reduced energy use in July, August and September, compared with the preceding months but it is not clear how much of this can be attributed to the upgrade and how much to the summer holiday period.

\section{Discussion and conclusions}

It has been demonstrated that, by engaging with the BM and other building users, and providing them with a means to observe the impact of their own actions, the energy culture in the building has changed, giving rise to more energy awareness and personal responsibility. The reduction in lighting and small power energy use, both during working 
hours and 'out of hours', has been achieved largely by the building users. In this context the FMs themselves are considered building users, as management of the building is only an additional responsibility over and above their normal user duties. Their direct interventions and day to day work and communication with their user colleagues have been key factors in the reductions achieved. These have been supported by the automated feedback mechanisms allowing people to see whether their combined efforts are being successful. Feedback is an essential part of the process and has helped to motivate users, some of whom were sceptical about the project at the initial stages. Lights are now used more sparingly during working hours and more are being turned off when the building is not in use. The results show that generally the reduction in energy use is being maintained, and that the behaviour change is more than just a short-term phenomenon. However, the 2011 data for February, March and April does appear to show a slight upward trend in the unoccupied electricity use. This coincides with a period of fewer communications with users compared with the same period in 2010, and may indicate that continuing behaviour reinforcement is still required. This should become clearer over the following months. However, this highlights one of the key features of the theory behind the techniques employed on the project, which is the need to keep going round the feedback loop on a continuous basis, improving and reinforcing behavioural change. Overall the project has delivered energy and carbon emission savings. However, based on the October 2009 to January 2010 baseline, and the associated mean daily savings of $77 \mathrm{kWh}$ over 246 'occupied' days and $38 \mathrm{kWh}$ over 119 'unoccupied' days, the projected annual savings are in the order of 23,000 kWh, equivalent to around $14 \mathrm{tCO}_{2} \mathrm{e}$. This represents over $20 \%$ saving in electricity usage for small power and lighting, and equates to an annual cost saving of around $£ 1600$, based on an electricity price of $7 \mathrm{p} / \mathrm{kWh}$.

Future planned improvements includes installation of wireless CTs in the west half of the building to supplement the exiting sub-meters and to allow the same level of diagnosis across the whole building. There is clearly a general buildings application for the techniques applied in this project and its' initial success has prompted similar work in other UoR buildings. 


\section{Acknowledgements}

This work is part of the Carbon Brainprint project funded by the Higher Education Funding Council for England (HEFCE). Acknowledgment is given to colleagues at the University of Cranfield for leading the project and Carnego Systems Ltd for their invaluable contribution to the case study conducted at Reading.

\section{Disclosure statement}

No potential conflict of interest was reported by the authors.

\section{References}

Aghahossein, M. M., R. Tetlow, M. Hadi, S. El-Jouzi, A. A. Elmualim, J. Ellis, and M. Williams. 2015. "Providing Persuasive Feedback through Interactive Posters to Motivate Energy-Saving Behaviours." Intelligent Buildings International 7 (1): 16-35.

Ajzen, I. 1991. "The Theory of Planned Behaviour." Organisational Behaviour and Human Decision Processes, 50: 179-211.

Atkin, B., and A. Brooks. 2005. Total Facilities Management. 2nd ed. Oxford: Blackwell Publishing. Beart, P. 2010. Personal Communication (Alert-Me in Cambridge).

Becker, F. 1991. The Total Workplace - Facilities Management and the Elastic Organisation. New York: Van Nostrand Reinhold.

Booy, D., K. Liu, B. Qiao, and C. A. Guy. 2008. Semiotic Model for a Self Organising Multi-Agent System, DEST2008 - International Conference on Digital Ecosystems and Technologies. Phitsanulok: IEEE.

Bordass, B., R. Cohen, M. Standeven, and A. Leaman. 2001. “Assessing Building Performance in Use 2: Technical Performance of the Probe Buildings.” Building Research and Information 29 (2): 103-113. Bordass, B., and A. Leaman. 2005. "Making Feedback and Post-Occupancy Evaluation Routine 3: Case Studies of the Use of Techniques in the Feedback Portfolio.” Building Research and Information 33(4): 361-375.

Chatterton, J., D. Parsons, J. Nicholls, P. Longhurst, M. Bernon, A. Palmer, F. Brennan et al. 2015. "Carbon Brainprint - an Estimate of the Intellectual Contribution of Research Institutions to Reducing Greenhouse Gas Emissions." Process Safety and Enviromental Protection 96: 74-81.

Clements-Croome, D. J. In press. "Sustainable Intelligent Buildings for People." International Intelligent Buildings 3 (2).

Clements-Croome, D. J. 2004. Intelligent Buildings: Design, Management and Operation. London: Thomas Telford.

Clifford, C., A. A. Elmualim, and F. Child. 2007. "Pervasive Technologies for Workspace Management at Nationwide Building Society." In CIB World Building Congress: Construction for 
Development, 755- $767 . \quad$ Holland: Cape Town.

http://site.cibworld.nl/db/publication/browserecord.php?-action=browse\&- recid=1039.

Duangsuwan, J., and K. Liu. 2008. "Multi-Agent Control of Shared Zones in Intelligent Buildings.'International Conference on Computer Science and Software Engineering 1 (12-14): $1238-1241$.

Elmualim, A. 2013. "Chapter 13: Sustainable and Intelligent Facilities Management." In Intelligent Buildings: Design, Management and Operation. 2nd ed., edited by D. Clements-Croome, 197213. London: Thomas Telford.

Elmualim, A. A., A. Czwakiel, R. Valle, G. Ludlow, and S. Shah. 2009. "The Practice of Sustainable Facilities Management: Design Sentiments and the Knowledge Chasm: in Emitt, S. (Guest Editor), Special Issue: Design Management for Sustainability." Architectural Engineering and Design Management 5(1/2), 91-102.

Elmualim, A. A., and A. Pelumi-Johnson. 2009. "Application of Computer-Aided Facilities Management (CAFM) for Intelligent Buildings Operation.” Facilities 27 (27): 421-428.

Elmualim, A., and D. Shockley, R. Valle, G. Ludlow, and S. Shah. 2010. "Barriers and Commitment of Facilities Management Profession to the Sustainability Agend." Building and Environment 45 (1): 58-64.

Himanen, M. 2003. "The Intelligence of Intelligent Building: The Feasibility of the Intelligent Building Concept in Office Buildings." PhD. VTT, VTT Publications.

Himanen, M. 2004. "The Intelligence of Intelligent Buildings." In Intelligent Buildings: Design, Management and Operation, edited by D. Clements-Croome, 25-52. London: Thomas Telford.

Keller, J., and C. Keller. 2004. "Bringing Strategic Efficacy to Facilities Management Through CAFM Tools." Facilities Management, 3 (2): 125-144.

Leaman, A., and B. Bordass. 2006. "Productivity in Buildings: The Killer Variables." In Creating the Productive Workplace, edited by Clements- Croome. 2nd ed. 153-180. London and New York: Taylor \& Francis.

Liu, K., C. Lin, and B. Qiao. 2008. "A Multi-agent System for Intelligent Pervasive Spaces." Proceedings of IEEE International Conference on Service Operations and Logistics, and Informatics (SOLI) 1005- 1010.

Noy, P., K. Liu, D. J. Clements-Croome, and B. Qiao. 2007. Design Issues in Personalising Intelligent Buildings. Proceedings of 2nd International Conference on Intelligent Environments, Athens, July 5- 6, IET.

Qiao, B., K. Liu, and C. Guy. 2006. A Multi-Agent System for Building Control, Proceedings of IEEE/WIC/ ACM International Conference on IAT, December 2006, Hong Kong.

Qiao, B., K. Liu, and C. Guy. 2007. Multi-Agent Building Control in Shared Environment, Proceedings of the 9th Int Conf on Enterprise Information Systems, 12-16, June 2007, Madeira, Portugal. 
Rapoport, R. N. 1970. “Three Dilemmas in Action Research.” Human Relations 23: 499-513. Shah, S. 2007. Sustainable Practice for the Facilities Manager. Oxford: Blackwell Publishing.

Stringer, E. T. 1999. Action Research: A Handbook for Practitioners. 2nd edn. San Francisco, CA: Sage Publications.

Teicholz, E. 1992. Computer-aided Facilities Management. New York: McGraw-Hill.

Tetlow, R., P. Beaman, A. Elmualim, and K. Couling. 2014. "Simple Methods to Reduce Inadvertent Energy- consumption in Non-domestic Buildings." Building and Environment 81 (2014): 234242.

Way, M., and B. Bordass. 2005. "Making Feedback and Post-occupancy Evaluation Routine 2: Soft Landings - Involving Design and Building Teams in Improving Performance." Building Research and Information 33 (4): 353-360.

Wong, J. K. W., H. Li, and S. W. Wang. 2005. "Intelligent Building Research: A Review." Automation in Construction 14: 143-159.

Wong, J., H. Li, and J. Lai. 2008. "Evaluating the System Intelligence of the Intelligent Building Systems: Part 1: Development of Key Intelligent Indicators and Conceptual Analytical Framework." Automation in Construction 17: 284-302.

Yin, R. K. 2009. Case Study Research: Design and Methods. 4th ed. 5 vols. Applied Social Research Methods Series, London: Sage. 